\title{
Measurement and Simulation of Induced Voltage and Current on 110 KV Crossing Transmission Lines under UHV AC Transmission Lines
}

\author{
Weiwei Pan1, Shoucheng Miu1, Guangkai Yu², Tian Wu², Bo Zhang3 \\ ${ }^{1}$ State Grid Jinhua Power Supply Company, Jinhua, China \\ ${ }^{2}$ China Electric Power Research Institute, Wuhan, China \\ ${ }^{3}$ School of Electrical Engineering, Wuhan University, Wuhan, China \\ Email: yarchergk@163.com
}

How to cite this paper: Pan, W.W., Miu, S.C., Yu, G.K., Wu, T. and Zhang, B. (2017) Measurement and Simulation of Induced Voltage and Current on $110 \mathrm{KV}$ Crossing Transmission Lines under UHV AC Transmission Lines. Energy and Power Engineering, 9, 635-643.

https://doi.org/10.4236/epe.2017.94B069

Received: February 24, 2017

Accepted: March 30, 2017

Published: April 6, 2017

\begin{abstract}
The induced electricity of $110 \mathrm{kV}$ transmission lines which cross the UHV AC transmission lines may threaten personal safety of the maintenance staff. In this paper, field measurement of the induced voltage and induced current on a $110 \mathrm{kV}$ crossing line inside Jinhua in Zhejiang province is performed. The electrostatic induced voltage on the measured line is $12.24 \mathrm{kV}$. The power frequency electromagnetic field simulation model is established, and the calculation results are consistent with the measured. Influence factors analysis shows that the electrostatic induced voltage on the $110 \mathrm{kV}$ line is $12.78 \mathrm{kV}$, the electromagnetic induced voltage is $12.3 \mathrm{~V}$, the induced current through ground wire is less than $1 \mathrm{~A}$ when the UHV lines operate at full load. The induced voltage and current decrease while the crossing distance increases. $\mathrm{Pa}$ rallel lines induction is much higher than crossing lines. The electromagnetic induced voltage after ground knife-switch shut down would exceed the human safety voltage $36 \mathrm{~V}$ while the crossing angle is less than $30^{\circ}$, so the temporary ground wire must be hanged to ensure safety of the maintenance staff.
\end{abstract}

\section{Keywords}

UHV AC Transmission Lines, Crossing, Induced Voltage, Induced Current, Field Measurement, Simulation Calculation

\section{Introduction}

Ultra-high-voltage AC power transmission has outstanding advantages of high transmission capacity, long distance of power transmission, low line loss, small 
coverage, etc., which is an energy-saving and eco-friendly advanced power transmission technology. At present, China has three $1000 \mathrm{kV} \mathrm{AC} \mathrm{UHV} \mathrm{projects}$ completed in operation in total [1] [2]. As construction of UHV lines is underway, it is inevitable that power transmission lines in other voltage classes may parallel or cross with UHV lines in construction due to space limitation of power transmission corridor [3] [4] [5]. While high-voltage lines are running, electromagnetic fields may arise in space surrounding the lines. As a result, induced voltage and current may arise in nearby low-voltage lines, triggering potential safety threats in low-voltage line shutdown overhaul [6] [7] [8]. As UHV lines have high running voltage and transmission power, it is more necessary to focus on their induced power on low-voltage lines.

Domestic and foreign studies on UHV AC power transmission line induction are more concerned with parallel construction. In Literature [9] [10], computation and field measurement are made on induced voltage and current in $500 \mathrm{kV}$ one-tower two-circuit parallel line; in Literature [11] [12] [13], simulated computation and analysis are made on induced voltage and current in two-circuit UHV line with one line in power and one line in shutdown and $1000 \mathrm{kV}$ UHV and $500 \mathrm{kV} / 220 \mathrm{kV}$ lines parallel with each other on the same tower respectively; in Literature [14] [15], computation is made on induction of UHV AC power transmission lines on low-voltage power distribution lines below. Concerning line crossing, in Literature [16] [17], methods of computation of power-frequency electromagnetic fields in crossing areas of AC power transmission lines are introduced; in Literature [18], theoretical computation is made on electrostatic induction of crossing and elongating conductors below $500 \mathrm{kV}$ power transmission line. Few systematic domestic and foreign studies are concerning power transmission line crossing induction.

In this paper, field measurement is made on induced voltage and current of $110 \mathrm{kV}$ crossing lines below UHV line in Jinhua, Zhejiang, simulated model is set up by CDEGS software to compute and analyze fluctuations in induced voltage and current of $110 \mathrm{kV}$ lines under different transmission currents of UHV line, different crossing distances and crossing angles between UHV and $110 \mathrm{kV}$ lines, precautions in shutdown overhaul of low-voltage lines under UHV line are presented, and reference basis is offered for layout design of crossing lines.

\section{System Overview and Simulation Model}

Put into operation at the end of 2014, Zhebei-Fuzhou 1000kV UHV AC Power Transmission Project is constructed in two circuits all the way. Line Jianglian I, Line Jianglian II and $110 \mathrm{kV}$ Line Xianchi 1555 (construction in two circuits on the same tower) cross in Jinhua. Their crossing distance is $18.3 \mathrm{~m}$ and crossing angle is $60^{\circ}$. Figure 1 shows layout of conductors and ground wires at the crossing location of two lines. G1 and A1-C1 refer to ground wire and threephase conductor of Line Jianglian I; G2 and A2-C2 refer to ground wire and three-phase conductor of Line Jianglian II. Conductor 1-3 and Conductor 4 - 6 refer to Line Xianchi 1555 Circuit I and Line Xianchi 1555 Circuit II respective- 


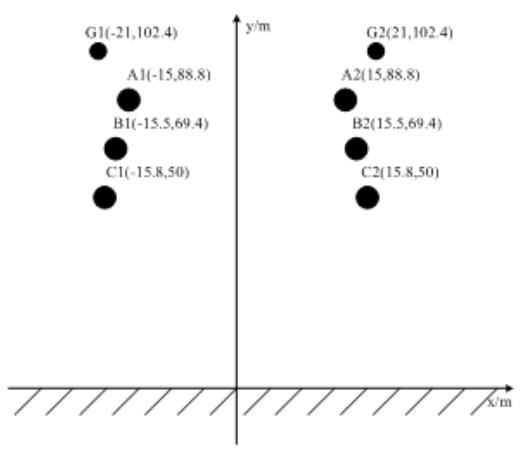

(a)

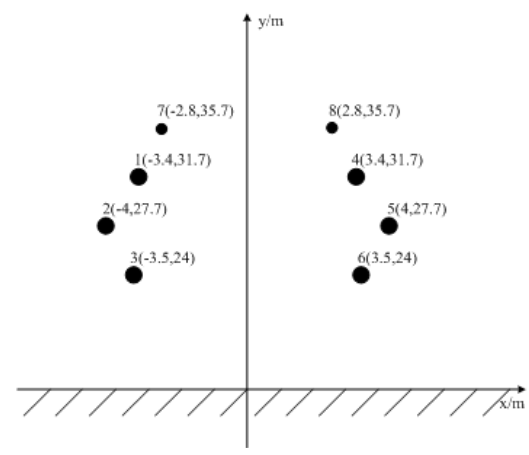

(b)

Figure 1. Layout of conductors and ground wires at the crossing location. (a) Line Jianglian; (b) Line Xianchi 1555.

ly; 7 and 8 refer to ground wires. Parameters of conductors and ground wires of crossing lines are shown in Table 1.

The simulated model of induced power of crossing lines is set up in the HIFREQ module in the simulation software of CDEGS as shown in Figure 2. Since induction is weaker somewhere farther from the crossing point, $2 \mathrm{~km}$ is taken as line length in simulated modeling, the crossing point is located in the center of line and line is deemed as a straight line by omitting the angle of rotation of line at the tension support; while power-frequency voltage and current are inflicted on three-phase conductor of Line Jianglian in normal operation, induction is computed in shutdown of Line Xianchi 1555.

\section{Measurement of Induced Voltage and Current of $110 \mathrm{KV}$ Line}

In order to study and master effects of UHV line on induced power of power transmission lines below, field measurement is made on $110 \mathrm{kV}$ Line Xianchi 1555 in Jinhua as shown in Figure 3. In measurement, $110 \mathrm{kV}$ line is in shutdown due to substation overhaul. In the state of test run, UHV line has lower load and its running load is as shown in Table 2.

In the measurement, three-phase conductors of Circuit I and Circuit II at the No.15 Support below the crossing point or Conductor 1 - 6 in Figure 1(b) are selected. Measured results are shown in Table 3.

1) Induced voltage of all phase conductors is measured before earthing switches on both ends of line are closed following substation shutdown;

2) After earthing switches on both ends of line are closed, induced voltage of all phase conductors is re-measured;

3) Temporary ground wires are attached to locations near both sides of a measuring point to measure induced current of temporary ground wires.

It is known by measured results that while earthing switches in the substation are not closed, higher electrostatic induced voltage arises on the $110 \mathrm{kV}$ line and induced voltage of Conductor 1 that is the closest to UHV line attains as high as $12.24 \mathrm{kV}$; while earthing switches on both ends of substation are closed, induced voltage on the line is almost zero; due to lower running load of UHV line in 
Figure 2. Simulated model.

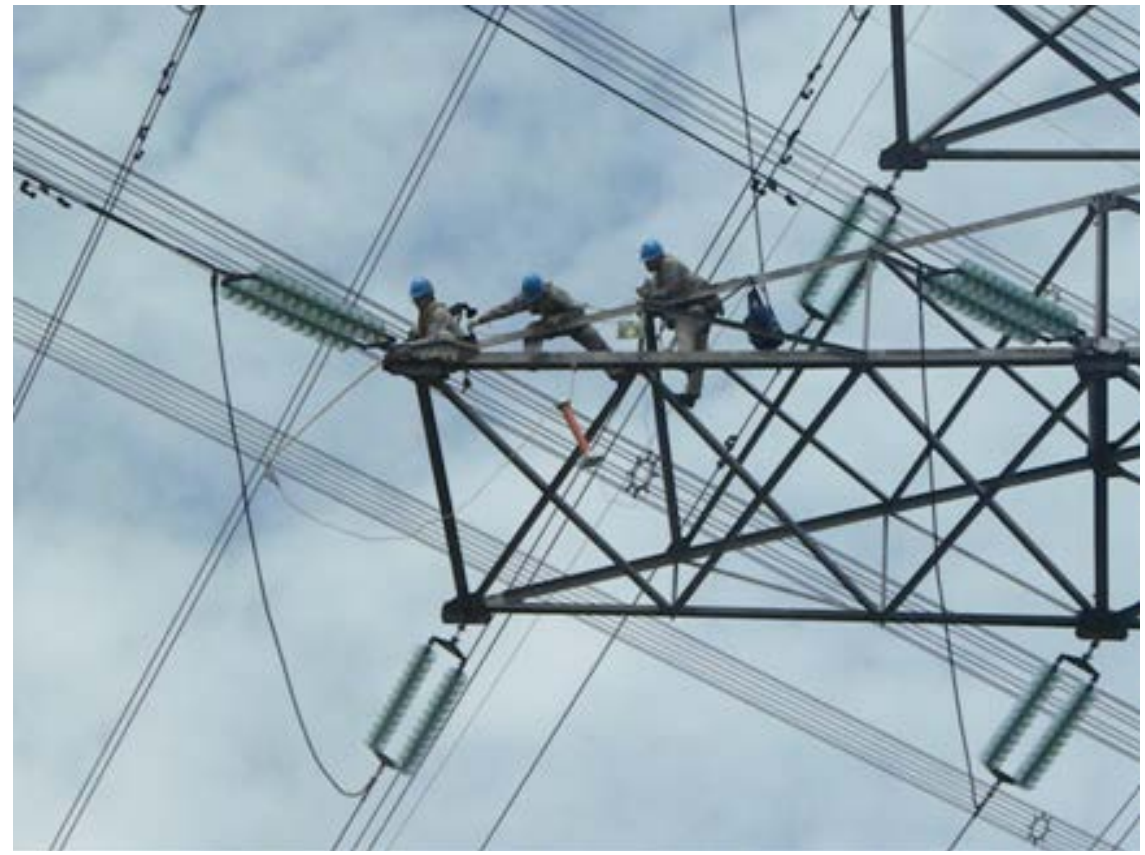

Figure 3. Induced voltage and current of crossing lines in field measurement.

Table 1. Parameters of conductors and ground wires of crossing lines.

\begin{tabular}{ccc}
\hline Line type & Line Jianglian & Line Xianchi 1555 \\
\hline Conductor & $8 \times$ JL/G1A-630/45 & $1 \times$ LGJ-240/30 \\
Ground wire & LBGJ-185-20AC & LGJ-50/30 \\
\hline
\end{tabular}

Table 2. UHV line load.

\begin{tabular}{ccc}
\hline \multirow{2}{*}{$\begin{array}{c}\text { Load } \\
\text { Parameter }\end{array}$} & \multicolumn{2}{c}{ Name of UHV line } \\
\cline { 2 - 3 } & Line Jianglian I & Line Jianglian II \\
\hline Active power/MW & $246-275$ & $241-271$ \\
Reactivepower/Mvar & $405-416$ & $11-21$ \\
Current/A & $261-271$ & $127-154$ \\
\hline
\end{tabular}


Table 3. Measured results of induced voltage and current.

\begin{tabular}{cccc}
\hline \multirow{2}{*}{$\begin{array}{c}\text { Conductor } \\
\text { No. }\end{array}$} & \multicolumn{2}{c}{ Induced voltage of conductor/kV } & $\begin{array}{c}\text { Induced current } \\
\text { of ground wire/A }\end{array}$ \\
\cline { 2 - 4 } 1 & Earthing switches are unclosed & Earthing switches are closed & 0.07 \\
2 & 12.24 & 0.002 & 0.06 \\
3 & 10.47 & 0.002 & 0.02 \\
4 & 8.70 & 0.002 & 0.07 \\
5 & 12.22 & 0.001 & 0.06 \\
6 & 10.47 & 0.001 & 0.02 \\
\hline
\end{tabular}

measurement, after temporary ground wires are attached to both ends of the crossing point, the measured induced current flowing through the ground wires is very low as well, which is lower than $0.07 \mathrm{~A}$.

\section{Simulated Computation and Analysis of Influence Factors}

The maximum value in Table 2 is taken as load of UHV line to make simulated computation on results of induced voltage of all conductors and induced current of temporary ground wires as shown in Table 4.

It is known by table that results of simulated computation and field measurement are close to each other, proving the accuracy of simulated model. Different transmission currents of UHV line, crossing distances and crossing angles are taken to make simulated computation and analysis on induced voltage and current of $110 \mathrm{kV}$ line.

\subsection{Effects of Transmission Current of UHV Line}

The maximum transmission capacity of the UHV line is $6000 \mathrm{MW}$ in one circuit. However, since it is put into operation lately and experiences no peak of power consumption, it keeps running in a lower load. In order to ensure personal safety in shutdown overhaul of $110 \mathrm{kV}$ line below, it is necessary to study induction in the state of high load. While UHV line is in the transmission powers of $2000 \mathrm{MW}, 4000 \mathrm{MW}$ and $6000 \mathrm{MW}$ respectively, transmission current of each phase conductor is $1.15 \mathrm{kA}, 2.31 \mathrm{kA}$ and $3.46 \mathrm{kA}$ respectively. Crossing distance of $18.3 \mathrm{~m}$ and crossing angle of $60^{\circ}$ are taken to compute induced voltage and current of $110 \mathrm{kV}$ line under different transmission currents as shown in Table 5.

While earthing switches in the substation are not closed, induced voltage of $110 \mathrm{kV}$ line is generally electrostatic coupling component and electrostatic induction is irrelevant with transmission current. Therefore, induced voltage of conductors is almost unchanged; after earthing switches on both sides of station are closed, induced voltage of $110 \mathrm{kV}$ line is generally electromagnetic coupling component and electromagnetic coupling voltage rises as transmission current rises in direct proportion and induced voltage is $12.3 \mathrm{~V}$ while UHV line is in 
Table 4. Results of simulated computation on induced voltage and current.

\begin{tabular}{cccc}
\hline \multirow{2}{*}{$\begin{array}{c}\text { Conductor } \\
\text { No. }\end{array}$} & \multicolumn{2}{c}{ Induced voltage of conductor/kV } & $\begin{array}{c}\text { Induced current } \\
\text { of ground wire/A }\end{array}$ \\
\cline { 2 - 3 } 1 & Earthing switches are unclosed & Earthing switches are closed & 0.067 \\
2 & 12.77 & 0.0016 & 0.057 \\
3 & 11.08 & 0.0013 & 0.044 \\
4 & 9.58 & 0.0014 & 0.067 \\
5 & 12.76 & 0.0016 & 0.057 \\
6 & 11.07 & 0.0013 & 0.044 \\
\hline
\end{tabular}

Table 5. Computing results of UHV line under different transmission currents.

\begin{tabular}{cccc}
\hline \multirow{2}{*}{$\begin{array}{c}\text { Transmission } \\
\text { current/kA }\end{array}$} & \multicolumn{2}{c}{ Induced voltage of conductor/kV } & $\begin{array}{c}\text { Induced current } \\
\text { of ground wire/A }\end{array}$ \\
\cline { 2 - 3 } & Earthing switches are unclosed & Earthing switches are closed & 0.20 \\
2.15 & 12.77 & 0.0047 & 0.38 \\
2.31 & 12.78 & 0.0085 & 0.56 \\
3.46 & 12.78 & 0.0123 & 0.035 \\
\hline
\end{tabular}

full-load operation; induced current flowing through temporary ground wires is very low, which is lower than $1 \mathrm{~A}$.

\subsection{Effects of crossing Distance between $110 \mathrm{KV}$ Line and UHV Line}

Transmission current of $3.46 \mathrm{kA}$ of each phase conductor and crossing angle of $60^{\circ}$ are taken to compute induced voltage and current of $110 \mathrm{kV}$ line under different crossing distances as shown in Table 6.

The farther UHV line is away from $110 \mathrm{kV}$ line below, the lower electrostatic induced voltage and electromagnetic induced voltage of $110 \mathrm{kV}$ line will be. As crossing distance rises from $20 \mathrm{~m}$ to $50 \mathrm{~m}$, electrostatic induced voltage falls from $12.43 \mathrm{kV}$ to $8.93 \mathrm{kV}$ and electromagnetic induced voltage falls from $12.2 \mathrm{~V}$ to $11.0 \mathrm{~V}$; induced current of temporary ground wires slightly declines as well.

\subsection{Effects of crossing Angle between $110 \mathrm{KV}$ Line and UHV Line}

Transmission current of $3.46 \mathrm{kA}$ of each phase conductor and crossing distance of $18.3 \mathrm{~m}$ are taken to compute induced voltage and current of $110 \mathrm{kV}$ line under different crossing angles as shown in Table 7.

While crossing angle changes from $0^{\circ}$ (parallel construction) to $90^{\circ}$ (vertical crossing), induced voltage and current of $110 \mathrm{kV}$ line show greater change. In parallel construction of two lines, electrostatic induced voltage attains $100.84 \mathrm{kV}$, electromagnetic induced voltage attains $358 \mathrm{~V}$, and induced current of ground wires attains 16.3 A, much higher than those in the situation of line crossing. Even though crossing angle is only $30^{\circ}$, electrostatic induced voltage falls $59.3 \%$, electromagnetic inducted voltage and induced current of ground wires fall as much as $89.7 \%$ and $89.4 \%$ respectively. 
Table 6. Computing results under different crossing distances.

\begin{tabular}{cccc}
\hline \multirow{2}{*}{$\begin{array}{c}\text { Crossing } \\
\text { distance/m } \mathrm{m}\end{array}$} & \multicolumn{2}{c}{ Induced voltage of conductor/kV } & $\begin{array}{c}\text { Induced current } \\
\text { of ground wire/A }\end{array}$ \\
\cline { 2 - 3 } 20 & 12.43 & Earthing switches are unclosed & Earthing switches are closed \\
30 & 10.84 & 0.0122 & 0.56 \\
40 & 9.755 & 0.0118 & 0.54 \\
50 & 8.930 & 0.0114 & 0.53 \\
\hline
\end{tabular}

Table 7. Computing results under different crossing angles.

\begin{tabular}{cccc}
\hline \multirow{2}{*}{$\begin{array}{c}\text { Crossing } \\
\text { angle }\end{array}$} & \multicolumn{2}{c}{ Induced voltage of conductor $/ \mathrm{kV}$} & $\begin{array}{c}\text { Induced current } \\
\text { of ground wire/A }\end{array}$ \\
\cline { 2 - 3 } & Earthing switches are unclosed & Earthing switches are closed & 16.3 \\
\hline $0^{\circ}$ & 100.84 & 0.358 & 1.72 \\
$30^{\circ}$ & 41.02 & 0.0367 & 0.56 \\
$60^{\circ}$ & 12.78 & 0.0123 & 0.039 \\
$90^{\circ}$ & 10.94 & 0.00088 & \\
\hline
\end{tabular}

\section{Conclusions}

- While $1000 \mathrm{kV}$ Line Jianglian is in liveoperation in Jinhua, Zhejiang, field measurement is made on induced voltage and current of conductors of 110 $\mathrm{kV}$ Line Xianchi 1555 that is $18.3 \mathrm{~m}$ below the above line and in a crossing angle of $60^{\circ}$ with the above line. The electrostatic induced voltage attains 12.24 $\mathrm{kV}$. Due to lower line load in measurement, the electromagnetic induced voltage is lower than $2 \mathrm{~V}$ and induced current of ground wires is lower than $0.07 \mathrm{~A}$.

- Results of simulated computation show that while UHV line is in full-load operation, electrostatic induced voltage is $12.78 \mathrm{kV}$, electromagnetic induced voltage is $12.3 \mathrm{~V}$ and induced current is lower than $1 \mathrm{~A}$ in the $110 \mathrm{kV}$ line below; as the crossing distance rises, the induced voltage and current gradually fall; while two lines are in parallel construction, the electrostatic induced voltage is $100.84 \mathrm{kV}$, electromagnetic induced voltage is $358 \mathrm{~V}$ and induced current of ground wires is $16.3 \mathrm{~A}$, much higher than those in the situation of line crossing. The higher the crossing angle is, the lower induced voltage and current will be.

- Though induced voltage and current of the crossing line below the UHV line are lower than those in parallel construction, greater electrostatic induced voltage may arise. In shutdown overhaul, it is necessary to ensure that earthing switches on both sides of line in the substation are closed. While crossing angle of lines is lower than $30^{\circ}$, electromagnetic induced voltage of lines will be higher than human safety voltage of $36 \mathrm{~V}$ after earthing switches are closed. Thus, in line overhaul, it is also necessary to attach temporary ground wires on both sides of a working point to ensure personal safety. 


\section{References}

[1] Liu, Z.Y. (2013) Innovation of UHVAC Transmission Technology in China. Power System Technology, 37, T1-T8.

[2] Liu, Z.Y. (2013) UHVAC/DC Power Grid. China Electric Power Press, Beijing.

[3] Shu, Y.B. and Zhang, W.L. (2007) Research of Key Technologies for UHV Transmission. Proceedings of the CSEE, 27, 1-6.

[4] Xiao, D.P., Jiang, K.R., Zhang, Z.L., et al. (2015) Optimization Algorithm for Arranging Extra-and Ultra-High Voltage Transmission Lines Subjected to the Constraints of Power Frequency Electromagnetic Environment Condition. Proceedings of the CSEE, 35, 2333-2341.

[5] Hu, S.S., Li, J., Ma, L., et al. (2012) Ground Clearance and Crossing Clearance of $\pm 1100 \mathrm{kV}$ UHVDC Transmission Line. Electric Power Construction, 33, 25-28.

[6] Tanen, J.D. and Wilson, G.L. (1971) Electrostatically Induced Voltages and Currents on Conducting Objects under EHV Transmission Lines. IEEE Transactions on Power Apparatus and Systems, 90, 341-349.

[7] Lin, C., Chuang, H. and Chen, K. (1990) Steady-state and Shock Currents Induced by ELF Electric Fields in a Human Body and a Nearby Vehicle. IEEE Transactions on Electromagnetic Compatibility, 32, 59-65. https://doi.org/10.1109/15.45251

[8] Wang, C.Y. (2010) The Reason and Protection Measurement of" Induced Electricity" inTransmission Lines Maintanence. Electrical Security Technology, 12, 6-12.

[9] Hu, D.H., Tu, C.Q., Jiang, W., et al. (2008) Calculation of Inductive Voltage and Current for $500 \mathrm{kv}$ Double Circuits Transmission Lines on Single Tower. High Voltage Engineering, 34, 1927-1931.

[10] Guo, Z.H., Yao, J.X., Cheng, X.Q, et al. (2006) StudyandMeasurementofInducedVoltageandCurrentfor500kVDoublyCircuitLineonSameTower.High VoltageEngineering, 32, 11-14,50.

[11] Li, B.J. and Zhou, H. (2011) Calculation and Analysis on Induced Voltage and Current of $1000 \mathrm{kV}$ Transmission Line Adopting Structure of Double Circuit on the Same Tower. Power System Technology, 35, 14-19.

[12] Liu, H.J, Yan, G.Z., Wang, S.H, et al. (2015) Analysis of Electrostatic Induced Voltageon $1000 \mathrm{kV}$ Wannan-Zhebei UHVAC Transmission Line. High Voltage Engineering, 41, 1687-1693.

[13] Li, Z.Q., Liu, C.Q., Dai, M., et al. (2013) Induced Voltage and Induced Current on AC Same-Tower Four-Circuit Lines Comprised of Double-Circuit $1000 \mathrm{kV}$ Lines and Double-circuit $500 \mathrm{kV}$ or $220 \mathrm{kV}$ Lines. High Voltage Engineering, 39, 3022-3028.

[14] He, Y.W., Liu, Y.K., Yan, N.N., et al. (2015) Evaluation of Induced Voltage and Current on Low-Voltage Distribution Lines under EHV/UHVAC and DC Transmission Lines. Power System Technology, 39, 2640-2646.

[15] Abdel-Salam, M. and Al-Shehri, A. (1994) Induced Voltages on Fence Wires and Pipelines by AC Power Transmission Lines. IEEE Transaction on Industry Applications, 30, 341-349. https://doi.org/10.1109/28.287525

[16] Chen, N., Wen, X.S., Lan, L., et al. (2011) Accurate Calculation of Three- Dimensional Power Frequency Electromagnetic Field for Space Crossed Transmission Line. High Voltage Engineering, 37, 1752-1759.

[17] Wang, X.Y., Zhao, J.G., Wu, X., et al. (2011) Calculation Method of Electric Field Intensity for AC Crossing Transmission Lines. High Voltage Engineering, 37, 
$411-416$

[18] Shao, F.Y. (1983) Electrostatic Induced Voltage and Current of Elongation Shaped Conductors under $500 \mathrm{kV}$ Transmission Lines. Electrical Technology, 5, 2-7.

Submit or recommend next manuscript to SCIRP and we will provide best service for you:

Accepting pre-submission inquiries through Email, Facebook, LinkedIn, Twitter, etc. A wide selection of journals (inclusive of 9 subjects, more than 200 journals)

Providing 24-hour high-quality service

User-friendly online submission system

Fair and swift peer-review system

Efficient typesetting and proofreading procedure

Display of the result of downloads and visits, as well as the number of cited articles Maximum dissemination of your research work

Submit your manuscript at: http://papersubmission.scirp.org/

Or contact epe@scirp.org 